\title{
AS SEÇÕES E GÊNEROS COMO PRÁTICA DA LÍNGUA PORTU- GUESA NOS JORNAIS: JORNAL DO COMMERCIO E CORREIO MERCANTIL
}

\section{THE SECTIONS AND GENDERS AS PRACTICE OF THE PORTU- GUESE LANGUAGE IN THE NEWSPAPERS: JORNAL DO COMÉR- CIO E CORREIO MERCANTIL}

\author{
José Alcides Ribeiro*
}

RESUMO: Um fenômeno que se destaca nos jornais de grande tiragem nos séculos XIX e XX é a organização dos gêneros literários e jornalísticos em seções. Essa prática revela uma clara exploração da dimensão lexical da Língua Portuguesa, que leva o leitor, na sua memória de médio e longo prazo, a ter na mente um perfil geral do que pode encontrar. Nessa prática, é eterna a exploração da língua na sua perspectiva de vocabulário e de dicionário. $\mathrm{O}$ texto que se segue apresenta uma caracterização das seções, de dois jornais de grande circulação, o Jornal do Commercio (1827-2008) e o Correio Mercantil (1848-1868) do Rio de Janeiro.

PALAVRAS-CHAVE: Jornais e revistas no Brasil, gêneros jornalísticos e gêneros híbridos, Jornal do Commercio e Correio Mercantil.

ABSTRACT: An outstanding phenomenon presented in all great newspapers printed in large scale in the XIX and XX centuries, is the organization of the literary and journalistic kinds at each section. This practice shows a clear exploration in the lexical dimension of the Portuguese Language, which leads the reader, in his medium and long term memories, to bear in mind a general profile of what he may find. In this practice, the exploration of the language in its perspective of vocabulary and dictionary is ever lasting. The text that follows presents a characterization of the sections of two newspapers of great circulation, the Jornal do Commercio (1827-2008) and the Correio Mercantil (1848-1868) from Rio de Janeiro.

KEY WORDS: newspapers and magazines in Brazil, journalistic and mixed kinds, Jornal do Commercio and Correio Mercantil.

\footnotetext{
* Professor na graduação e na pós-graduação do Departamento de Letras Clássicas e Vernáculas da Universidade de São Paulo. Líder do Grupo Temático Comunicação, Literatura e Jornalismo do CNPQ. Autor dos livros Imprensa e Ficção no Século XIX, Transdisciplinaridade: Literatura Brasileira e Jornalismo/Correio Mercantil, Transdisciplinaridade: Literatura Brasileira e Jornalismo/Jornal do Commercio.
} 



\section{AS SEÇÕES E GÊNEROS COMO PRÁTICA DA LÍNGUA PORTUGUESA NOS JORNAIS: JORNAL DO COMMERCIO E CORREIO MERCANTIL}

\section{O Comunicado Sintético na Seção Gazetilha do Jornal do Comércio}

Já na década de cinqüenta pode-se encontrar a presença da seção Gazetilha no Jornal do Comércio. O gênero explorado era o comunicado sintético e a temática explorava as notícias sobre os fatos variados. Na década de oitenta aparece um título em negrito para cada notícia. Ver no dia 8 de janeiro de 1880, página 1 , o seguinte comunicado:

Biblioteca Municipal. - Durante 21 dias do mês próximo findo, foi essa biblioteca freqüentada por 287 leitores, que consultaram 355 obras, sendo: teologia 1, jurisprudência 10, ciências e artes 118, belas letras 102, historia, geografia, viagens, etc. 20, jornais, revistas, mapas, enciclopedias, etc. 96 .

Essas obras são escritas nas seguintes línguas: portuguesa 190, francesa 152, italiana 2, espanhola 6, inglesa 4, grega 1. (Jornal do Commercio, 8 jan. 1880, p. 1)

Ver no exemplar do dia 16 de janeiro de 1884, página 1, outro comunicado típico da seção. O trecho é o seguinte:

"Linhas Telefônicas - Consta-nos que por decreto n. 9115 de 5 de janeiro corrente foi autorizado Antônio Pinto da Silva a assentar nas cidades de S. Paulo e Campinas, sendo expresso que a concessão não importa privilégio de qualquer espécie”. (Jornal do Commercio, 16 jan. 1884, p. 1) 
Na década de oitenta, a Gazetilha, passou a agregar um rol diversificado de gêneros jornalísticos. No dia $1^{\circ}$ de julho de 1887 , página 1 , o jornalista faz um relato sobre as atividades da família imperial. É uma típica reportagem. Veja-se o seguinte trecho: "Os alunos do internato Pedro II, formados em alas, saudaram Suas Majestades em sua passagem, e defronte do Clube Atlético a banda do Instituto dos Cegos, que estava em um bonde, executou o Hino Nacional".

\section{O Comunicado Sintético na Seção Telegramas do Jornal do Comércio}

$\mathrm{O}$ gênero explorado era o comunicado sintético. As temáticas giravam em torno dos fatos jornalísticos em geral, cujas notícias eram enviadas por telegrama. Ver, na página 3, dia 9 de janeiro de 1874, as notícias sobre o câmbio em Londres e Nova Iorque, sobre a venda de mil sacas de café em Santos, as cotações do café em Londres e o preço do algodão em Santos. Se foi uma seção que apareceu timidamente definida em termos gráficos, ocupando menos da metade de uma coluna, já no final do ano, no dia 24 de dezembro de 1874, página 2, apareceu com título em caixa alta, ocupando duas colunas, com notícias da Agencia Havas-Reuter. Nesse dia podem ser encontradas notícias sobre a vida de políticos e notícias sobre as cidades de Roma, Madri, Paris, Pernambuco, Londres. O formato do comunicado reproduzia o do telegrama. Veja-se, como exemplo, o seguinte trecho:

23 de Dezembro às 6 horas da tarde. Na sessão de hoje da Assembléia Nacional de Versalhes, a esquerda pediu que fosse interpelado o governo acerca da ordem que se cassou de não dar prosseguimento ao negócio da Junta Bonapartista do Apelo ao Povo. Este pedido foi aprovado. O ministério declarou que estava pronto a responder a esta interpelação, que virá proximamente. (JORNAL DO COMÉRCIO, p. 2, 24 DEZ. 1874).

Seções de crônicas do Folhetim do Jornal do Commercio

\section{Ver, Ouvir e Contar}

Esta seção já aparecia nas páginas do jornal em 1877, com crônicas sem assinatura, apresentando características de crônica jornalística. A temática ligava-se aos fatos jornalísticos da vida na Europa, na França e em Paris. Na crônica do dia 10 dez. 1887, o cronista comenta "[...] um caso bem parisiense." que originou "[...] um verdadeiro escândalo na imprensa e nas 
rodas teatrais de Paris[...]" e que ficou conhecido como "A Questão do Comediante", fruto dos atritos resultantes das críticas mordazes de um cronista contra um comediante muito conhecido e das reações dele e do meio contra o jornalista cronista, polêmica acontecida nas páginas do jornal $O$ Figaro (Le Figaro). Na crônica do dia 20 de julho de 1881, página 1, o autor relata como está sendo construído um túnel no Canal da Mancha e oferece informações sobre a Exposição Internacional de Eletricidade a ser realizada no Palácio dos Campos Elíseos em Paris. Na crônica do dia 6 de janeiro de 1880, página 1, o autor reclama das condições do seu trabalho de cronista no exterior. $\mathrm{O}$ trecho é o seguinte:

O ofício de cronista é duro mister pelo tempo que corre. Morar num quinto andar-que os franceses, com os seus elegantes eufemismos, chamam de quarto [...]. Não achar uma carruagem para ir à caça de notícias, e por mais de seus pecados, ter, custe o que custar, de alinhavar um folhetim - será isto então vida regalada? (JORNAL DO COMÉRCIO, p. 1, 6 jan.1880)

Em outras crônicas pode-se notar a focalização dos aspectos relativos à vida rica e pobre em Paris. O resultado dessa temática é a apresentação nas crônicas de quadros pitorescos sobre os passeios da alta sociedade no Bois de Boulogne, sobre os aspetos miseráveis e desastrosos do inverno na cidade, sobre as dificuldades da população trabalhadora em comprar o caro carvão de Paris para aquecer as casas. O autor separa os temas com um espaço em branco com estrelinhas. No dia 6 de janeiro de 1880, o autor explora quatro temas, separados graficamente: o inverno em Paris, os jornais, as revistas e os parisienses e um interessante comentário sobre o comportamento prático dos ingleses, informa que eles inventaram naquele ano "[...] um sistema de cozinha nos comboios que devem percorrer um longo trajeto [...]”. Destaca que a invenção é importante, pois faz o viajante livrar-se da exploração dos restaurantes nas estações.

$\mathrm{Na}$ crônica do dia 23 de julho de 1885, página 1, o autor denuncia o roubo da invenção do mecanismo da fotografia, executado por Daguèrre, junto ao seu sócio Niceforo Niepce, residente no interior França no começo do século XIX. Em grande parte das crônicas desta seção, o temas e fatos jornalísticos selecionados são trabalhados com ironia, como é o caso do dia 18 de setembro de 1886, em que o cronista comenta a descoberta do italiano João Súcia, de uma planta no centro da África que provocava a atonia do es- 
tomago e possibilitava o jejum de sessenta dias àquele que bebesse a poção da planta. O cronista compara o inventor a Jesus Cristo e observa que "[...] está resolvida a questão social [...]”, pois as pessoas poderão ganhar “[...] o sustento de quatro meses no ano".

\section{Palestra}

Esta seção apareceu em 1887, assinada por Nemo e continuou por alguns anos. O autor tem uma clara opinião formada sobre a imprensa, acha que "[...] é preciso ter a coragem de dizer a verdade, por mais dura que ela seja [...]" e que no seu ponto de vista “[...] esta missão cabe à imprensa." (JORNAL DO COMÉRCIO, 29 dez. 1887). O autor desenvolve comentários sobre fatos jornalísticos de interesse geral. Na crônica do dia 23 de dezembro de 1887, ele comenta que teve a idéia de mandar imprimir os textos e apresenta a sua idéia de livro "[...] escuso acrescentar que eu queria uma edição como nunca houve igual aqui: impressão primorosa, papel acetinado, gravuras de Heck e o meu retrato feito no Guimarães." (JORNAL DO COMÉRCIO, 23 dez. 1887).

Os temas das crônicas da seção eram extremamente variados e boa parte deles eram explorados com a ironia e a paródia. No dia 9 de julho de 1887, página 1, o cronista opina sobre a influência do francês do Brasil. Assumindo um tom jocoso relativo à imitação do modelo francês de viver observa que o francês "[...] dentro em pouco será também a língua oficial do Brasil". Parodiando os jornais que dedicam uma seção diária "[...] à descrição das toilettes [...] das senhoras que passam pela Rua do Ouvidor [...]”, o autor chama a atenção para a utilização disseminada de vocábulos da Língua Francesa e em relação à presença de produtos franceses no Rio de Janeiro. Veja-se, como exemplo, o interessante trecho que se segue:

Há ainda outra questão pendente: De onde vem o Português? Muita gente afiança que vem em linha reta do Latim. Para o jornalista não existe a menor dúvida a tal respeito: o português vem do francês. Exemplos: Toilette, toilette; misé-en-scène, mise-en scéne, réclame, réclame, poste-restante, posta-restante, boudoir, boudoir, etc, etc. / À vista destes e de muitos outros exemplos, que eu poderia citar, está provado que o português vem do francês...para o jornalista, bem entendido . (Os itálicos são do autor). (JORNAL DO COMÉRCIO, P.1, 9 jul. 1887). 


\section{Correio Mercantil do Rio de Janeiro}

\section{As Seções do Correio Mercantil}

O Correio Mercantil foi publicado na cidade do Rio de Janeiro de $1^{\circ}$ de janeiro de 1848 a 15 de dezembro de 1868. Nos anos iniciais da década de cinqüenta, o jornal era editado em francês aos domingos. No início de 1848 , o cabeçalho do jornal trazia o nome da firma do proprietário, Francisco José dos Santos Rodrigues e Companhia. No cabeçalho vinha registrado, também, o preço da assinatura na corte (trimestral: quatro mil réis- $4 \$ 000$, semestral: oito mil réis-8 $\$ 000$, anual: dezesseis mil réis-16\$000) e nas províncias (trimestral: cinco mil réis- $5 \$ 000$, semestral: dez mil réis-10\$000, anual: 20\$000). Um aviso destacava que os artigos e comunicados de interesse geral teriam inserção gratuita e que as assinaturas poderiam ser feitas na Rua da Quitanda. No final do rodapé da página quatro, havia a indicação de que o jornal era impresso no prelo mecânico da Tipografia do Correio Mercantil de propriedade de Francisco José dos Santos Rodrigues e Cia., na Rua da Quitanda, 13. Em 1855 muda o proprietário, o cabeçalho do jornal menciona como dono J. F. Alves Moniz Barreto.

Um exemplar característico do Correio Mercantil possuía quatro páginas com textos ligados a gêneros jornalísticos informativos e literários bastante variados. Cada página era organizada geralmente em cinco colunas separadas por filetes pretos. Os textos ligados aos gêneros informativos apareciam em todas as páginas. Na primeira e na segunda página, eram inseridas geralmente as seções denominadas Exterior, Interior, Variedades, Rio de Janeiro - Notícias e Fatos Diversos, Folhetim do Correio Mercantil. Os textos pertencentes aos gêneros literários eram veiculados na primeira e na segunda página, muito raramente na terceira e apareciam nas seções Folhetim do Correio Mercantil e Pacotilha. Na terceira página, apareciam as seções Correspondências, Publicações a Pedido, Avisos, Leilões e Anúncios. Na quarta página, os anúncios ocupavam a quase totalidade do espaço gráfico.

\section{O Comunicado nas Seções do Correio Mercantil}

As seções denominadas Exterior, Interior, Rio de Janeiro: Notícias e Fatos Diversos ofereciam, respectivamente, notícias sobre a Europa, Estados Unidos da América e Ásia, sobre o interior do país e sobre a cidade do Rio de Janeiro. O tipo de gênero explorado era o comunicado. 
Veja-se, a seguir, um típico comunicado:

“- SS. MM.II e as sereníssimas princesas continuarão a gozar de perfeita saúde."

SS.MM. estiveram na corte desde 30 de dezembro até ontem às 3 horas e meia da manhã, em que se retiraram para Petrópolis.

Tiveram a honra de cumprimentar a SS.MM. na corte os Srs. General Cabral, Guarda-Roupa João Teixeira, Marquês de São João Marcos e sua senhora, Dr. Feital, Tavares de Itaguaí, Monsenhor Narciso, Bispo eleito do Maranhão/.../ e Dr. Saturnino de Souza Oliveira.

Entrarão de semana os Srs: Dom José, camarista; José Manoel Carlos, viador; Teixeira de Macedo, guarda-roupa; Dr. Tomás Gomes, médico “(CORREIO MERCANTIL, p.1, 5 jan. 1852.)

Um travessão colocado no início do parágrafo distinguia um comunicado do outro, não havendo nenhuma outra separação, o fato era relatado no seu aspecto seqüencial, o tom e o léxico empregados eram formais, sem gíria ou alusões cômicas.

\section{Os Romances na Seção Folhetim do Correio Mercantil}

O espaço gráfico da seção Folhetim do Correio Mercantil abrigava textos isolados ou muitas seções especiais de crônicas, críticas ligadas a várias áreas do conhecimento e textos ficcionais variados: contos, romances europeus traduzidos e romances brasileiros. Os romances seriados, publicados em pedaços, ocupavam geralmente o rodapé das duas primeiras páginas, parte localizada da metade para baixo e graficamente isolada por um traço em negrito. Nesse espaço surgiram os romances Os Dois Amores, de Joaquim Manuel de Macedo, em 1848, e A Providência, de Teixeira e Sousa. A seguir, estão relacionadas as seções que constituíam a seção geral Folhetim do Correio Mercantil.

\section{As Crônicas da Seção Folhetim do Correio Mercantil}

Representativa em alto grau do tipo de crônica publicada na seção Folhetim do Correio Mercantil é a crônica "Boas festas/ Ao ano de 1848", publicada em 2 de janeiro de 1848, página 1, sem a assinatura do seu respectivo criador. $\mathrm{O}$ autor inicia o texto destacando que 1848 é ano bissexto e que, neste caso, as velhas habitualmente fazem previsões negativas, limitando-as, 
o autor toma a liberdade de fazer um grande prognóstico (presságio, previsão) para 1848, seguindo, no entanto, o caminho inverso das velhas senhoras, prevendo, somente coisas positivas.

Por centro temático das previsões, o autor da crônica elege, então, inúmeros fatos noticiosos da vida quotidiana do Rio Janeiro de 1847, muitos deles encontráveis fartamente na própria seção Rio de Janeiro - Notícias e Fatos Diversos do Correio Mercantil ou em qualquer outra seção de variedades dos jornais do período. Nessa crônica, o material noticioso que aparece nas seções informativas dos jornais sob a forma tradicional do comunicado com travessão no início do parágrafo passa por um processo de condensação e assume um caráter essencialmente ficcional.

A escolha dos fatos noticiosos possibilita a formação de um contraste entre o passado real e um hipotético futuro, pois o prognóstico fixa um conjunto de fatos positivos que deveriam acontecer e que são opostos aos fatos negativos ocorridos repetidamente nos anos anteriores e em 1847.

\section{Quadro Geral das Previsões para o Ano de 1848}

Com o prognóstico, o autor projeta o seguinte quadro geral de práticas vitais nas diferentes esferas de convivência dos cariocas:

\section{Os Serviços Públicos}

O autor indica que os cartórios não demorarão em emitir certidões, a recebedoria do município não emitirá mais documentos em termos pouco precisos, as autoridades da Capitania dos Portos não farão mais vistas grossas e multarão todos os navios que atropelem os botes por não reduzir o número de remos ao entrar no porto, o correio funcionará perfeitamente, os fiscais e guardas da alfândega não esconderão a sua identificação, não faltará água nos bairros de São Cristóvão, Benfica e Praia Pequena e todas as calçadas da cidade deverão ser pavimentadas segundo o tipo das calçadas da Rua do Ouvidor.

\section{O Comportamento e os Hábitos dos Cariocas}

O autor prevê que não ocorrerá mais o problema do excesso de bebidas nos barcos que transportam as famílias para as festas da Penha e de Paquetá, os passageiros das gôndolas não fumarão mais charutos, os escritórios dos ônibus estarão sempre abertos de manhã. Nas hortas dos moradores da cidade, serão plantadas somente as melhores sementes e nas reuniões familiares 
será oferecido o chá “[...] do melhor que há [...]" (CORREIO MERCANTIL, p. 1, 2 jan. 1848), aos amigos.

\section{A Segurança da Cidade}

No que se relaciona com o problema da presença massiva dos capoeiras nas ruas e nas praças da cidade, o autor sugere que a solução será a aplicação pela polícia do açoite nos cativos e o recrutamento dos libertos para a marinha, para o exército ou para a armada, onde poderão gingar à vontade. Sugere, também, que os desocupados e os desordeiros tenham o mesmo destino e que sejam deixados de fora os cidadãos tranqüilos e desocupados.

\section{A Publicidade nos Periódicos}

Será abolido o uso de óculos, pois a maravilhosa água de Tobias realizará curas espantosas e radicais. Todos serão gordos, porque o Xarope do Bosque terá sarado os tísicos; já as tinturas de cabelo, novidade na época, darão a todos a lindíssima "cor fogo" ou a cor preta, eliminando os cabelos brancos (CORREIO MERCANTIL, p. 1, 2 jan. 1848).

\section{As Práticas Culturais}

Os teatros deverão apresentar peças musicais com "modinhas brasileiras", evitando, assim, apresentações de peças em línguas estrangeiras. $\mathrm{O}$ fogo do divino deverá começar às dez horas da noite. A "Revista Brasileira" deverá esgotar o "[...] seu repertório de cousas do século passado [...]" e somente “[...] tratar de cousas do século presente [...]" (CORREIO MERCANTIL, p. 1, 2 jan. 1848).

\section{O Comportamento das Mulheres}

Ao comentar o comportamento das mulheres, o autor cria uma galeria de tipos paródicos, explorando a presença da ironia disfemística, perceptível nos epítetos qualificadores que aparecem sempre grifados em itálico. Observa que as "belas beatas" não levarão cachorros às missas, atrapalhando, assim, o cerimonial com seus latidos, as "belas tolas" não darão amostras dos seus sovaquinhos lisos, as "belas diletantes" não levarão crianças aos teatros que atrapalhem as peças, as "belas mal ensaiadas" disfarçarão artificialmente os seus defeitos, as "belas pobres de espírito" articularão casamentos cujos pretendentes estejam interessados no dinheiro, as "belas 
escarninhas" ficarão solteironas por castigo, as "belas descoradas" não se pintarão com pinturas exageradas que realcem ainda mais a falta de cor, as "belas escolhedeiras" escolherão o pior que se lhes oferecer, as "belas passeantes" continuarão a ter cavalheiros de braços para encher os intervalos e as "belas bailantes" terão par fixo (CORREIO MERCANTIL, p. 1, 2 jan. 1848).

O autor termina a crônica com o seguinte trecho:

Eis, pois, leitores e leitoras os prognósticos do ano de 1848, que Deus conserve com os seus 366 dias frescos, e outras tantas noites de belo luar ou de lampiões acesos para regalo da alma, e segurança das nossas vidas e das nossas bolsas. (CORREIO MERCANTIL, p. 1, 2 jan. 1848)

Na verdade, o prognóstico cumpre a função de estabelecer um contraste e serve para destacar os defeitos e problemas reais da cidade e dos seus habitantes. Nessa maneira de representar a cidade pode-se perceber a presença de uma focalização que se apóia na ironia disfemística (deformante) e na sátira. $\mathrm{O}$ autor da crônica distingue-se por ser um profundo crítico de costumes e por apresentar um quadro geral do meio social do Rio de Janeiro, das suas instituições sociais, do comportamento dos seus habitantes e dos seus hábitos.

\section{Os Gêneros na Seção Pacotilha do Correio Mercantil}

A seção Pacotilha saía uma vez por semana e ocupava as duas primeiras páginas do jornal, às vezes abrangia até uma parcela da terceira página. A seção apresentava no início do espaço gráfico dois títulos em caixa alta, ambos separados visualmente por um filete preto da maneira como se segue:

\section{COMUNICADO \\ PACOTILHA}

O exame dos textos da seção indica que essa organização gráfica era uma técnica chamariz dos redatores do jornal para atrair a atenção dos leitores acostumados com os comunicados noticiosos tradicionais, mas não refletia verdadeiramente os tipos de gênero de texto veiculados pela seção. No seu conjunto, a Pacotilha funcionava como uma micro-enciclopédia jornalística e literária, pois abrigava no seu espaço gráfico notícias sobre o 
interior, o exterior, fatos diversos na forma dos comunicados tradicionais, comunicados com comentários, diálogos alegóricos, cartas comentadas e romances seriados.

O vocábulo "Factura" e um sumário temático das notícias e dos textos apareciam sempre no alto da primeira coluna. O entrelaçamento dos vocábulos "pacotilha" e "factura" dava à seção um aspecto satírico e simultaneamente paródico relativo ao próprio jornal. No Dicionário Contemporâneo da Língua Portuguesa, que abrange os séculos XIX e XX, Caldas Aulete (1970, V. II, p. 1558 , V. IV, p. 2632), registra para o termo pacotilha os significados de "[...] porção de gêneros que o passageiro podia levar consigo no navio ou gêneros que o capitão do navio ou algum passageiro ia vender [...]", gêneros em geral de inferior qualidade, "[...] artefato grosseiro ou malacabado [...]", "fancaria", já no que toca ao termo "factura" o autor registra os significados de "[...] mapa e conta da carga que compreende toda a carregação do navio [...]”, “[...] relação de mercadorias vendidas a qualquer [...]", "[...] maneira pela qual uma obra /.../ foi feita e pela qual se conhece o gênio distintivo do autor [...]" ou "[...] conta por miúdo que se forma do valor de uma mercadoria para servir de norma à venda [...]”. O tom satírico da seção desencadeava efeitos junto à opinião pública carioca. O exemplar do dia 6 de janeiro de 1952, página 3, trazia duas respostas às críticas do Carijó. Uma delas era a do mestre de música do $5^{\circ}$ Batalhão da Guarda Nacional, justificando-se no que concerne a um problema relativo ao fardamento, a outra era de um morador da Rua do Senhor dos Passos, exigindo esclarecimentos sobre a crítica do Carijó sobre um clarinetista morador na mesma rua que incomodava a vizinhança com os seus exercícios musicais.

A seção Pacotilha funcionava como uma micro-enciclopédia jornalística e literária dentro do Correio Mercantil, pois no seu espaço gráfico eram publicadas crônicas, notícias sobre o interior e o exterior, comentários. Iniciou como seção em 10 de fevereiro de 1851 e terminou em 1854. Saía geralmente às segundas-feiras nas páginas $1,2,3$, com uma numeração seqüencial. Era assinada pelo Carijó, que se tornou personagem da seção, junto com o Miguel e o Gregório. Depois do título, um sumário indicava os temas comentados no interior. Às vezes, romances eram publicados no espaço gráfico da Pacotilha, que se situava na parte superior das duas páginas iniciais, raramente no rodapé; assim veio a público o romance Memórias de um sargento de milícias de Manuel Antônio de Almeida de 1852 a 1853. A seção Pacotilha distinguiu-se das outras seções do Correio Mercantil pela 
genialidade da mistura do jornalístico e do literário e pelo tom extremamente satírico. O tipo de linguagem da seção era extremamente próximo do estilo de Manuel Antônio de Almeida, que deve ter escrito para ela um grande número de textos. No dia 9 de julho de 1854, primeira página, o redator do primeiro número da seção Páginas Menores comentou que a Pacotilha não poderia mais ser editada e observou que a sua característica principal era a de ser um "[...] escritório eivado, como todo escrito parcial, dos ódios e das animosidades daquele tempo [...]" e anunciou que "Nas páginas Menores encontrará o leitor a revista [...] e vários artigos sobre as belas letras e as belas artes, além do retrospecto político e industrial”. Merece severos reparos o tom conservador e oportunista desse redator que não assinou a matéria. A substituição da Pacotilha pela seção Páginas Menores funcionou como uma espécie de golpe de estado na criatividade jornalístico-literária e no perfil de tribuna política da primeira. Pouco tempo depois, José de Alencar, com a assinatura Al., iniciou as crônicas da subseção Ao Correr da Pena, com as características anunciadas no comentário aqui exposto. Teria sido ele o autor do comentário?

\section{Gêneros Jornalísticos: Comunicado Opinativo}

Um típico comunicado com comentário apresentava um fato noticioso com comentário do redator que no final da seção utilizava o pseudônimo Carijó e Comp. O exemplar do dia 5 de janeiro de 1852 traz um típico comunicado com comentário, localizado no primeiro parágrafo da primeira página. $\mathrm{O}$ tema do comentário é o julgamento sobre o ano de 1851 que passou, apresentado pelo Jornal do Comércio e pelo Correio Mercantil em números anteriores, jornais considerados pelo redator como os dois principais órgãos de publicidade no Rio de Janeiro. O redator procura evidenciar que o Jornal do Comércio tem um falso patriotismo, pois no comentário sobre o ano que passou "[...] encontrou só que louvar e nada que censurar [...]" e esqueceu de incluir-se no comentário sobre as melhorias materiais alcançadas pelo país, pois no "fogo do patriotismo" não lembrou de dizer "[...] quanto agadanhou a sua empresa do tesouro público nacional, quantos melhoramentos materiais por via dele obteve [...]" (CORREIO MERCANTIL, p.1, 5 mar. 1852). A alusão irônica é direta e pelo filtro da visão irônica é que passam as notícias apresentadas nos comunicados com comentário. 


\section{Gêneros Híbridos: Diálogo Alegórico}

Um típico diálogo alegórico era estruturado sempre em torno de um episódio de audiência no tribunal em que várias personagens faziam solicitações ao juiz Carijó. Assistido pelos auxiliares Antônio e Gregório, o juiz tomava medidas reparadoras. O diálogo evoluía sempre em torno das reivindicações de cada uma das personagens solicitantes, sendo emitidos juízos sobre fatos, costumes e personagens facilmente detectáveis na realidade do dia-adia da cidade. O exemplar do dia 5 de janeiro de 1852, páginas 1-2, traz um típico diálogo alegórico.

Um carvoeiro solicita que seja aberto um novo caminho da Gávea até o centro da cidade, pois no caminho velho caíram num buraco e morreram o seu burro de carga e a esposa. A senhora Umbelina faz várias reclamações. Uma delas é a de que o capitão que a trouxera da Europa havia feito falsas promessas de enriquecimento no Brasil. A outra é ligada ao seu último patrão, que a engravidara, mas negara a paternidade. Umbelina aproveita a oportunidade para pedir uma autorização para tornar-se ama de leite, mesmo após ter tido catapora e varíola, o que considera normal. $\mathrm{O}$ juiz indignado nega a autorização e convoca o patrão de Umbelina que é português. A senhora Verônica reclama do roubo das suas economias, efetuado por um seu patrício ao qual confiara as economias por ter caído doente e ter sido internada pelos médicos do hospital. O Senhor Anacleto reclama de um estudante de medicina que em vez de estudar promove bacanais e farras.

Nos diálogos há a mistura hábil de ficção e fatos noticiosos, configurando um processo de construção por hipertexto, no qual se misturam o fato noticioso e a ficção.

\section{Gêneros Jornalísticos: Cartas Enviadas}

Este gênero aparece separado graficamente dos outros com o título "Escritório da Pacotilha”. Assumindo o pseudônimo de Carijó, o redator comenta as cartas enviadas pelos leitores.

Fatos noticiosos ligados à vida quotidiana dos moradores da cidade são o centro dos comentários do redator. É uma técnica muito interessante para apresentar juízos sobre os problemas da cidade e da população com uma visão satírica, humorística e sarcástica, utilizando uma linguagem informal, com inúmeras gírias e com um humorismo absolutamente próximo da atmosfera dos pasquins. 
A seguir, vejam-se três fragmentos bastante representativos do Escritório da Pacotilha:

Mande dizer àquele sujeito morador da Rua da Alfândega, com estabelecimento defronte de certo botequim, que seja mais humano e civilizado com os seus subordinados ou caixeiros, chegando ao arrojo de dar-lhes bofetadas, como ainda ultimamente fez com um com quem é relacionado pelos laços de sangue, como foi público e notório. (CORREIO MERCANTIL, p. 2, 5 fev. 1852)

Peça ao chefe de polícia lance suas vistas sobre os bárbaros castigos praticados diariamente sobre os cinco aprendizes/.../de charuteiro, em uma fábrica da Rua de D. Manoel quase em frente ao Beco da Boa Morte. (CORREIO MERCANTIL, p. 2, 5 fev. 1852)

Vizinha a essa mesma casa existe um senhor/.../ que também há dias quebrou um dedo a uma escrava e foi preciso ir à Santa Casa para lhe ser cortado, como de fato foi. No caso de se querer averiguar o fato há provas (CORREIO MERCANTIL, p. 2, 5 fev. 1852, p. 2)

Dirigindo-se ao Gregório ou ao Antônio, o redator comenta o conteúdo das cartas recebidas de missivistas bastante insatisfeitos com o Rio de Janeiro e com o país. É importante perceber que as críticas do Carijó têm em mira fatos extremamente variados, situações e personalidades da vida pública e privada. Efetua-se aqui uma vigorosa crítica aos costumes dos vários grupos do campo social, com denúncias sobre as arbitrariedades, violências e abusos. Pode-se notar que a seção funciona como uma tribuna dos vários segmentos da sociedade.

É importante perceber que na atmosfera midiática do Correio Mercantil o tom de crítica aos costumes e o emprego da ironia aparecem não só nas crônicas e nos outros gêneros noticiosos, mas também estão presentes nos textos ficcionais de escritores do Correio Mercantil, dentre eles, Manuel Antônio de Almeida e Joaquim Manuel de Macedo, isto aponta para a presença de um fenômeno de contaminação de um gênero textual no outro e vice-versa. Outro fenômeno interessante é o do processo de criação por hipertexto em que há a mistura de ficção com fatos noticiosos, processo bastante explorado atualmente em romances-reportagem, várias reportagens do jornalismo impresso ou em programas do meio televisivo tal como o Linha Direta da Rede Globo de Televisão e outros. 
Para concluir é importante destacar que os tipos de modos de composição no Correio Mercantil deixam entrever no século XIX uma rica e exuberante imaginação literária e jornalística.

\section{Referências Bibliográficas}

CORREIO MERCANTIL. Rio de Janeiro: Tipografia do Correio Mercantil, 1848-1868.

JORNAL DO COMMERCIO. Rio de Janeiro. Tipografia do Jornal do Commercio, 1827-2008.

AGUIAR E SILVA, V. M. de. Teoria da literatura. 6a . ed. Coimbra: Livraria Almedina, 1984.

ALLEN, G. Intertextuality. London and New York: Routledge, 2002.

AMARAL, L. Jornalismo: Matéria de primeira página. Rio de Janeiro: Tempo Brasileiro; Fortaleza: Universidade Federal do Ceará, 1982.

BAHIA, J. Jornal, história e técnica: As técnicas do jornalismo. São Paulo: Ática, 1990.

lo: Ática, 1990.

. Jornal, história e técnica: história da imprensa brasileira. São Pau-

BAKHTIN, M. Problemas da poética de Dostoievski. Rio de Janeiro: Forense-Universitária, 1981.

. Estética da criação verbal. Trad. de Maria Ermantina Galvão G. Pereira. São Paulo: Martins Fontes, 2000.

BROOKS, B. S. et al. News reporting and writing. New York: Harcourt, 2000.

CALDAS AULETE. Dicionário Contemporâneo da Língua Portuguesa. 5a . ed. Rio de Janeiro: Delta, 1970,V. II, IV.

COIMBRA, O. O texto da reportagem impressa. São Paulo: Ática, 1993.

DEFLEUR, M. L. \& BALL-ROKEACH, S. Teorias da comunicação de massa. Trad. Octavio Alves Velho. Rio de Janeiro: Jorge Zahar Editor, 1993.

DIJK, Teun A. van. Traducción de Guillermo Gal La noticia como discurso: Comprensión, estructura y producción de la información. Barcelona: Paidós, 1990. 
FRED, F. et al. Reporting for the media. New York: Harcourt, 2000.

GARGUREVICH, J. Gêneros periodisticos. Quito: Belén, 1982.

GENETTE, G. Palimpsestes: La littérature au second degré. Paris: Seuil, 1983.

GOMIS, L. Teoria dels gèneres periodístics. Barcelona: Generalitat de Catalunya / Centre d'Investigació de la Comunicació, 1989.

HARRISS, J. \& LEITER, K. \& JOHNSON, S. The Complete reporter: Fundamentals of new gathering, writing and Editing. New York: Macmillan, 1992.

JAUSS, H. R. Littérature médiévale et théorie des genres. In: Théorie des genres. Org. Gérard Genette e Tzvetan Todorov. Paris: Du Seuil, 1986.

KUNCZIK, M. Conceitos de jornalismo. São Paulo: Edusp, 2001.

LIMA, A. A. O jornalismo como gênero literário. São Paulo: COM-ARTE e EDUSP, 1990.

LOTMAN, I. Estrutura do texto artístico. Trad. Maria do Carmo Vieira Raposo e Alberto Raposo. Lisboa: Estampa, 1978. . La semiosfera. Madri: Ediciones Cátedra, 1996.

. Universe of the mind. Translated by Ann Shukman. Bloomington \& Indianapolis: Indiana University Press, 1990.

MEDINA, C. de A. Notícia: um produto à venda. São Paulo: Alfa-Omega, 1978.

RABAÇA, C. \& BARBOSA, G.G. Dicionário de comunicação. São Paulo: Ática, 1987.

SAER, J. J. El Concepto de Ficion. Buenos Aires: Ariel, 1998.

SARDÁ, A. M. El surgimiento de la prensa de masas. In: El periodismo escrito. Org. Mar de Fontcuberta. Barcelona: Mitre, 1986.

SODRÉ, M. \& FERRARI, M. H. Técnica de reportagem: Notas sobre a narrativa jornalística. São Paulo: Summus, 1986.

STRUNK,W. and White E. B. The elements of style. New York: Rutledge, 2000.

TODOROV, T. Les Genres du discours. Paris: Du Seuil, 1978. 
USPENSKY, B. A poetics of composition. Translated by Valentina Zavarin and Susan Wittig. Berkeley, Los Angeles \& London: University of California Press, 1983.

VIVALDI, G. M. Curso de Redaccion. Madrid: Paraninfo, 1990. . Generos Periodisticos. Madrid, Paraninfo, 1979.

WARREN, C. N. Gêneros periodisticos informativos. Trad. Alfonso Espinet Gou. Barcelona: A.T.E., 1975. 